\title{
Study of clinical and ophthalmic symptoms of malignant hypertension
}

\author{
Telgote $\mathbf{V}^{1}$, Singh $\mathbf{A}^{2}$
}

${ }^{1}$ Dr.Vandana Telgote, Associate Professor, Index Medical College \& hospital and research Centre,Indore, ${ }^{2}$ Dr.Ankita Singh, PG Resident, Index Medical College \& hospital and research Centre,Indore, MP, India

Address for correspondence: Dr VandanaTelgote, Email: vandanatelgote@gmail.com

\begin{abstract}
Introduction: Malignant hypertension is high blood pressure that comes suddenly and quickly. We attempted to review the clinical and fundus findings in patients with malignant hypertension (MHT). The lower (diastolic) blood pressure reading which is normally less than $80 \mathrm{mmHg}$, is often above $130 \mathrm{mmHg}(240 / 140 \mathrm{mmHg})$. Malignant hypertension may present with retinopathy, choroidopathy, and optic neuropathy. Optical coherence tomography is a relatively new imaging technique for evaluating retinal thickness and the location of pathology in patients with malignant hypertension.

Material and Methods: A retrospective observational study was carried in the department of ophthalmology comprising two groups based on history of history of hypertension (group1)and no history of hypertension (group2). The charts and fundus photographs of patients with hypertensive retinopathy from 2010 to 2015 was studied. Data of patients were included when their color photographs of the fundus were judged to indicate hypertensive retinopathy grade III or IV. There had to have been at least 1 high blood pressure reading recorded in the chart during the period when the symptoms occurred. Results: Twenty patients were included in our study. Patients were divided into 2 groups according to whether or not they had a history ofhypertension. Group 1 included 8 patients with no hypertension history, while group 2 included 12 patients with a known hypertension history. In group 1, Malignant hypertension was diagnosed by an ophthalmologist in 8 patients, in which 4:4 M:F ratio and In group 2, 12 patients of malignant hypertension, in which M:F ratio being 3:9.There were no significant differences in age, or systolic and diastolic blood pressures. There were more complications such as renal failure and stroke in group 2 patients. Conclusion: Funduscopy has decisive significance in the diagnosis and monitoring of MHT. In order to accurately diagnose and achieve early control of this critical condition, a detailed fundus examination and blood pressure monitoring are mandatory.
\end{abstract}

Key words: Malignant Hypertension, Malignant Hypertensive Retinopathy.

\section{Introduction}

Malignant hypertension is a known complication of hypertension. Primary or secondary hypertension due torenal or nonrenalcauses can be complicated by development of papilloedema and has a malignantcourse.Aggressive drug therapy with dialysis improves the prognosis in these patients.[1]. Ocularmanifestations of systemic hypertension are common and result in vascular compromise at the level of the retina, the choroid, or the optic nerve. The Beaver Dam Eye Study estimated that $10.7 \%$ of hypertensive patients over the age of 40 have hypertensive retinopathy and over a 5 -year follow-up period, $6 \%$ of

Manuscript received: $10^{\text {th }}$ July 2015

Reviewed: $29^{\text {th }}$ July 2015

Author Corrected: $8^{\text {th }}$ Aug 2015

Accepted for Publication: $14^{\text {th }}$ Aug 2015 those who had normal retinal exams developed hypertensive retinopathy [2].

Hypertensive retinopathy is the most common ocular sign of hypertension and is a result of the breakdown of the inner blood-retinal border. It is characterized by retinal arteriolar attenuation, so-called copper wiring of the retinal arterioles caused by sclerosis and hyalinization of the vascular wall, arteriovenous crossing changes ('nicking'), cotton-wool spots, and in advanced cases, retinal arteriolar exudation leading to a macular star [3]. Hypertensive optic neuropathy is less common and occurs when retinal ischemia causes swelling of the retinal ganglion cells. These cells travel from the inner retina and combine to form the optic nerve. Swelling in the optic nerve leads to optic nerve 
head elevation and flame-shaped hemorrhages [3]. Hypertensive choroidopathy, seen in combination with retinopathy and also known as hypertensive chorioretinopathy, is caused by fibrinoid necrosis of the choroidal arterioles and is characterized by hypoperfusion of the choriocapillaris (best seen with fluorescein angiography), break down of the retinal pigment epithelial cells causing hypopigmented lesions (Elschnig spots), and subsequent serous retinal detachments [4].

Hypertensive choroidopathy is an uncommon manifestation of hypertension seen in young patients secondary to an acute increase in blood pressure [5]. Its predilection for younger patients is not well understood but thought to be related to elasticity and pliability of younger blood vessels. The choroid is uniquely susceptible to acute rises in blood pressure due to the structure of this vascular network. The vessels of the choriocapillaris branch at right angles, leaving them more susceptible to acute blood pressure changes than the more acute branching vessels of the retina $[5,7]$.

The dramatic findings of hypertensive chorioretinopathy are associated with poor visual and systemic prognosis due to their association with systemic illnesses seen in young patients with acute rises in blood pressure: toxemia of pregnancy, renal disease, pheochromocytoma, andhypertensive emergency [8,7]. However, no published reports of incidence rates among patients with these systemic diseases exist in the literature. We report the case of a patient with hypertensive emergency whose primary symptom was vision loss due to hypertensive choriretinopathy.

The object of this study was to review the clinical and fundic manifestations in Malignant hypertension patients with new onset or acute exacerbation of chronic hypertension. The investigation also sought to determine if funduscopy has decisive significance in the diagnosis of MHT. So we searched for patients withMalignant hypertension, before thetarget organ damage had occurred or during early progression, when patients complained of such manifestationsof the fundus as an acute or sub-acute decrease in vision. Thus, we hope to be able to suggest early interventions for blood pressure control.

\section{Material and Methods}

The present study was a retrospective observational study conducted in the Department of ophthalmology, Index Medical College, Indore, MP. Twenty patients were included in our study. Patients were divided into 2 groups according to whether or not they had a history of hypertension.

Period of study- 2010-2015

\section{Inclusion criteria-}

1. Grade III or IV hypertensive retinopathy

2. There had to have been at least 1 high blood pressure reading recorded in the chart during the period when the symptoms occurred.

Exclusion criteria- diseases as diabetes mellitus,blood dyscrasia, and autoimmune and infectious diseases which can mimic the fundus findings of MHT

Collection of data- we retrospectively reviewed the chart and fundal photographs of patients with hypertensive retinopathy from 2010-2015. All patients had visited an ophthalmologic clinic with the chief complaint of blurred vision.Data of patients were included when their color photographs of the fundus were judged to indicate hypertensive retinopathy grade III or IV by an experienced ophthalmologistand undergone visual acuity examination. There had to have been at least 1 high blood pressure reading recorded in the chart during the period when the symptoms occurred. Data were excluded from patients with such diseases as diabetes mellitus, blood dyscrasia, and autoimmune and infectious diseaseswhich can mimic the fundus findings of MHT.

\section{Grading and staging of hypertensive retinopathy-}

Keith-Wagener-Barker classification (1939)

Patients were grouped according to their ophthalmoscopic findings. As such, this was the first system to correlate retinal findings with the hypertensive disease state. Classifications are as follows:

- Group 1- Slight narrowing, sclerosis, and tortuosity of the retinal arterioles; mild, asymptomatic hypertension

- Group 2- Definite narrowing, focal constriction, sclerosis, and AV nicking; blood pressure is higher and sustained; few, if any, symptoms referable to blood pressure 
- Group 3 - Retinopathy (cotton-wool patches, arteriolosclerosis, hemorrhages); blood pressure is higher and more sustained; headaches, vertigo, and nervousness; mild impairment of cardiac, cerebral, and renal function

- Group 4 - Neuroretinal edema, including papilledema; Siegrist streaks, Elschnig spots; blood pressure persistently elevated; headaches, asthenia, loss of weight, dyspnea, and visual disturbances; impairment of cardiac, cerebral, and renal function

Scheie classification (1953)

Staging under this system is as follows [9]:

- Stage 0 - Diagnosis of hypertension but no visible retinal abnormalities

- Stage 1 - Diffuse arteriolar narrowing; no focal constriction

- Stage 2 - More pronounced arteriolar narrowing with focal constriction

- Stage 3 - Focal and diffuse narrowing, with retinal hemorrhage
- Stage 4 - Retinal edema, hard exudates, optic disc edema

The Scheie classification also grades the light reflex changes from arteriolosclerotic changes, as follows [9]:

- Grade 0 - Normal

- Grade 1 - Broadening of light reflex with minimal arteriolovenous compression

- Grade 2 - Light reflex changes and crossing changes more prominent

- Grade 3 - Copper-wire appearance; more prominent arteriolovenous compression

Statistical Analysis-Statistical analysis was done by calculation of range, median, mean, standard deviation, percentage, odds ratio, chi square test and $\mathrm{p}$ value.

Statistical software: The statistical software SPSS 10.0 was used for the analysis of the data and Microsoft word and excel have been used to generate graphs, tables etc.

\section{Results}

Twenty patients were included in our study (Table 1). There were 8 males and 12 females. The patients were divided into 2 groups according to whether or not they had a history of hypertension.

Group 1 (cases 1 to 8 ) included 8 patients with no history of hypertension, while group 2 (cases 7 to 20) included 12 patients with a known history of hypertension. The ages ranged from 12 to 47 (mean, 31.2) years in group 1 and 22 to 56 (mean, 43.1) years in group 2.Systolic blood pressures ranged from 163 to 228 (mean, 206) mmHg in group 1 and 160 to 249 (mean, 196) $\mathrm{mmHg}$ in group 2. Diastolic blood pressure ranged from 100 to 160 (mean, 143) $\mathrm{mmHg}$ in group 1and 90 to 156 (mean, 115) $\mathrm{mmHg}$ in group 2. Patients in group 2 had a hypertension history with or without receiving medication for it. There were no significant differences in ages, or systolic and diastolic blood pressures between the 2 groups. Case 6 (group 1) developed renal failure 1 month after Malignant hypertension was diagnosed, although he was admitted for intensive medical blood pressure control. Two patients in group 2 experienced cerebral vascular accidents during the period when Malignant hypertension was diag nosed. Case 7 developed a central retinal artery occlusion (OS) contemporaneously with Malignant hypertension being diagnosed. $\mathrm{P}$ value was more than 0.5 which was not significant.

Table No 1: Demographic profile of groups

\begin{tabular}{|l|l|l|l|}
\hline & Group 1 & Group 2 & p value (student's t-test) \\
\hline No. of Cases & 8 & 12 & \\
\hline Mean Age(yrs) & $31(12-47)$ & $43($ range, 22-56) & 0.576 \\
\hline $\begin{array}{l}\text { Mean Systolic } \\
\text { Pressure(mmHg) }\end{array}$ & 206(range,160-128) & $196($ range, $160-249)$ & 0.543 \\
\hline $\begin{array}{l}\text { Mean Diastolic } \\
\text { Pressure(mmHg) }\end{array}$ & $140($ range, 100-180) & $115($ range, $90-156)$ & 0.460 \\
\hline Gender(M/F) & $4 / 4$ & $3 / 9$ & \\
\hline Etiology(No.) & $\begin{array}{l}\text { Essential Hypertension } \\
(4)\end{array}$ & Essential Hypertension(3) & \\
\hline & Renal Disease(3) & Renal Disease(4) & \\
\hline & Pheochromocytoma(1) & Pheochromocytoma(1) & \\
\hline & $\begin{array}{l}\text { Pregnancy Induced } \\
\text { Hypertension(1) }\end{array}$ & $\begin{array}{l}\text { Pregnancy Induced } \\
\text { Hypertension((3) }\end{array}$ & \\
\hline
\end{tabular}


Table No 2: Clinical, and Ophthalmic Findings of Patients

\begin{tabular}{|l|l|l|l|}
\hline & Group I[8] & Groupii[12] & $\begin{array}{l}\text { P value (student's t } \\
\text { test) }\end{array}$ \\
\hline Clinical features & 7 & 12 & 0.56 \\
\hline Visual acuity decreased & 5 & 7 & 0.6 \\
\hline $\begin{array}{l}\text { Fundal changes- retinopathy gd III } \\
\& \text { IV }\end{array}$ & 8 & 12 & 0.7 \\
\hline
\end{tabular}

Table No. 2 shows that out of 8 patients in group I 7 had clinical features of malignant hypertension while all patients in group II had features of malignant hypertension. Visual acuity decreased in 5 patients in group I and 7 patients in group II.on fundus examination all patients had grade III- IV hypertensive retinopathy. P value $>0.5$ which was not significant.

\section{Discussion}

A hypertensive emergency is defined as a sudden increase in systolic and diastolic blood pressure associated with end organ damage of the central nervous system, the heart, or the kidneys, and clinical evidence that a life-threatening event is present or nearly at hand[10]. Ahemd et al.[11] investigated the clinical features and survival rate of 200 consecutive patients with malignant hypertension and accelerated hypertension and with fundus lesions of grade 3 or 4 , and they concluded that malignant and accelerated hypertension were the same disease with similar clinical features and prognosis, similar to our study.

Shukla et al[12] found that the association between serous retinal detachment of macula (SRD) in hypertensive retinopathy (HTR) and malignant hypertension has been reported. This cross-sectional study included 14 consecutive patients on treatment for hypertension, who were referred for ophthalmic evaluation and were found to have macular SRD, documented by optical coherence tomography. All underwent systemic evaluation for hypertensive status and to rule out other associated/similar diseases such as diabetes, coagulopathies, lupus etc. The mean age of the patients was 44.35 +/- 15.5 years; the mean bestcorrected visual acuity was 6/12. All had grade 3-4 HTR; 10 patients had bilaterally symmetrical retinopathy (grade 3 or 4); 4 had asymmetric fundus changes. Systemically, every patient was found to have malignant hypertension. The mean systolic and diastolic pressures were $208.57+/-32.78$ and $117.86+/-14.2$ $\mathrm{mm} \mathrm{Hg}$, respectively. SRD predicted malignant hypertension more consistently than papilledema $(\mathrm{P}=$ .0132). The presence of macular SRD in a hypertensive patient may serve as an indicator of malignant hypertension.
Hypertensive emergencies and urgencies are important causes of morbidity and mortality. Malignant hypertension is a hypertensive urgency characterized by grade III/IV retinopathy and widespread endothelial damage[13]. Steinegger et al [14] investigated the types of symptoms and ocular lesions observed with ocular fundus examination, ocular fundus photography, fluorescein angiography and optical coherence tomography in a small case series of 7 patients with malignant hypertension.thay found that the Median systolic blood pressure (BP) was $205 \mathrm{mmHg} \pm 21$. Median diastolic BP was $150 \mathrm{mmHg} \pm 16$. Decrease in visual acuity (6/7 patients) and scotoma (5/7) were the main symptoms and Elschnig spot, flamed shaped haemorrhage, serous retinal detachment, cotton wool spots and optic nerve oedema were the five most frequently observed lesions. A regression of lesions was observed after therapy of systemichypertension.

In order to remind ourselves of the importance of early detection and intervention with acute hypertension before definite target organ damage occurs, we reviewed the clinical and ophthalmologic findings of patients with malignant hypertension.

According to the WHO classification, patients were included in our investigation when the observed severe hypertensive retinopathy was in stages III or IV. The systolic pressure in these patients should be higher than $160 \mathrm{mmHg}$, and the diastolic pressure higher than 90 mmHg. Hermann and Schubert reviewed past ophthalmologic studies and reported that the most frequently used definition of high blood pressure used in those studies was an elevated systolic blood pressure of $160 \mathrm{mmHg}$ or higher, or a diastolic blood pressure of $95 \mathrm{mmHg}$ or higher, in the absence of antihypertensive medicine [15-18]. Patients may visit ophthalmologists 
with symptoms that include reduced visual acuity secondary to either hypertensive retinopathy, choroidopathy, or optic neuropathy, or because of cortical disease causing transient loss of color vision, visual hallucinations, and ocular motility disorders[19].) Heidbreder et al. found that severe hypertensive retinopathy was observed in patients with renal hypertension, especially in focal segmental sclerosis and membranoproliferative glomerulonephritis [20].

There is no definition for typical "malignant hypertensive retinopathy" (MHR). Hayreh et al.[21] distinguished retinopathy, choroidopathy, and optic neuropathy based on an animal model of malignant renal arterial hypertension[21]. Retinopathy appeared significantly earlier than did either choroidopathy or optic neuropathy. Hayreh et al. also described focal intraretinalperiarterial transudates (FIPTs) as the specific retinal lesion of MHT [22].

As studied by Browning et al[23] the worst visual prognosis was associated with the highest presented blood pressure, the worst visual acuity at presentation, and the longest duration of symptoms. It is likely that the visual prognosis is affected by factors present at the time of presentation. So, early recognition is essential [23]. BV mittal et al[24] studied the Fortythree cases presenting with malignant hypertension (diastolic pressure above $120 \mathrm{~mm} \mathrm{Hg}$ associated with a grade IV change of retinopathy) were selected for this study. Nine cases presented for the first time with hypertension and were detected to have malignant hypertension.In 21 cases hypertension was detected less than a year ago while in 10 cases preexisting hypertension was present for more than a year, maximum duration being 10 years. Thirtysix cases were males. The age range was 10 years to 55 years, with maximum number of patients being in the $26-50$ year age group. On analysing the clinical data, oligoanuria $(86.04 \%)$, cardiac failure $(58.1 \%)$, decreased vision $(32.5 \%)$, and headache $(25.5 \%)$ were the main presenting symptoms.

Similar to our study Yi-HaoChenet al [25] studied Fourteen patients were included in our study. Patients were divided into 2 groups according to whether or not they had a history of hypertension. Group1 included 6 patients with no hypertension history, while group 2 included 8 patients with a known hypertension history. In group 1, MHT was diagnosed by an ophthalmologist in 4 patients, and the other 2 patients were referred from the Gynecology and Nephrology Departments. Between the 2 groups, there were no significant differences in age, or systolic and diastolic blood pressures. There were more complications such as renal failure and stroke in group 2 patients.

\section{Conclusion}

Hypertensive retinopathy is a common complication of systemic hypertension and it can be the harbinger of a potentially life-threatening hypertensive emergency with end-organ damage. Choroidal involvement in the setting of hypertensive emergency is usually the sign of an acute, dramatic increase in systemic blood pressure in a young person. It can be the presenting sign of undiagnosed hypertensive emergency or even a result of potentially life-threatening, secondary causes of systemic hypertension. An ocular fundus exam is imperative in any patient with concomitant visual symptoms and elevated blood pressure.

These data suggest that retinopathy and retinal arteriolar narrowing are common in people with hypertension. Further longitudinal study is necessary to evaluate the public health significance of these retinal lesions regarding possibly increased risk of renal and cardiovascular disease.

Funding: Nil,Conflict of interest: None. Permission of IRB: Yes

\section{References}

1. MOYER JH, HEIDER C, PEVEY K, FORD RV. The effect of treatment on the vascular deterioration associated with hypertension, with particular emphasis on renal function. Am J Med. 1958 Feb;24(2):177-92.

2. Klein R, Klein BE, Moss SE. The relation of systemic hypertension to changes in the retinal vasculature: the Beaver Dam Eye Study. Trans Am Ophthalmol Soc. 1997;95:329-48; discussion 348-50.

3.Wolffsohn JS, Hurcomb PG. Hypertension and the eye. CurrHypertens Rep.2002;4(6):471-6.

4. Hayreh SS, Servais GE, Virdi PS. Fundus lesions in malignant hypertension. VI. Hypertensive choroidopathy. Ophthalmology. 1986

Nov;93(11):1383-400.

5. Luo BP, Brown GC. Update on the ocular manifestations of systemic arterial hypertension. Curr Opin Ophthalmol. 2004 Jun;15(3):203-10. 
6. Tso MO, Jampol LM. Pathophysiology of hypertensive retinopathy. Ophthalmology. 1982 Oct;89(10):1132-45.

7. Bourke K, Patel MR, Prisant LM, Marcus DM. Hypertensive choroidopathy. J Clin Hypertens (Greenwich). 2004 Aug;6(8):471-2.

8. Bruce BB, Thulasi P, Fraser CL, Keadey MT, Ward A, Heilpern KL, et al. Diagnostic accuracy and use of nonmydriatic ocular fundus photography by emergency physicians: phase II of the FOTO-ED study. Ann Emerg Med. 2013;62(1):28-33. e1. doi:10.1016/j.annemergmed.2013.01.010.

9. World Health Organization. Arterial hypertension. World Health Organ Tech Rep Ser 1978;628:7-56.

10. Rodriguez MA, Kumar SK, De Caro M. Hypertensive crisis. Cardiol Rev. 2010 Mar-Apr. 18(2):102-7.

11. Ahmed ME, Walker JM, Beevers DG, Beevers M. Lack of difference between malignant and accelerated hypertension. Br Med J (Clin Res Ed). 1986 Jan 25;292(6515):235-7.

12. Shukla D, Ramchandani B, Vignesh TP, Rajendran A, Neelakantan N. Localized Serous Retinal Detachment of Macula as a Marker of Malignant Hypertension. Ophthalmic Surg Lasers Imaging. 2010 Mar 9. 1-7.

13. Kitiyakara C, Guzman NJ. Malignant hypertension and hypertensive emergencies. J Am Soc Nephrol. 1998 Jan;9(1):133-42.

14. Steinegger K, Bergin C, Guex-Crosier Y Malignant hypertension: clinical manifestations of 7 cases. KlinMonblAugenheilkd. 2015 Apr;232(4):590-2. doi: 10.1055/s-0034-1396333. Epub 2015 Apr 22

15. Schubert HD. Ocular manifestations of systemic hypertension. Curr Opin Ophthalmol. 1998 Dec;9(6):69-72.
16. Klein R. Retinopathy in a population-based study. Trans Am Ophthalmol Soc. 1992;90:561-94.

17. Klein R, Klein BE, Moss SE, Wang Q. Hypertension and retinopathy, arteriolar narrowing, and arteriovenous nicking in a population. Arch Ophthalmol. 1994 Jan;112(1):92-8.

18. Yu T, Mitchell P, Berry G, Li W, Wang JJ. Retinopathy in older persons without diabetes and its relationship to hypertension. Arch Ophthalmol. 1998 Jan;116(1):83-9.

19. Mathews KD. Hypertensive encephalopathy in childhood.J Child Neurol 1996;11:193-6.

20. Heidbreder E, Hüller U, Schäfer B, Heidland A. Severe hypertensive retinopathy. Increased incidence in renoparenchymal hypertension. Am J Nephrol. 1987;7(5):394-400.

21. Hayreh SS, Servais GE, Virdi PS, Marcus ML, Rojas P, Woolson RF. Fundus lesions in malignant hypertension. III. Arterial blood pressure, biochemical, and fundus changes. Ophthalmology. 1986 Jan;93(1):45-59.

22. Hayreh SS, Servais GE, Virdi PS. Fundus lesions in malignanthypertension: IV Focal intraretinalperiarterial transudates. Ophthalmology. 1986 Jan;93(1):60-73.

23. Browning AC, Mengher LS, Gregson RM, Amoaku WM. Visual outcome of malignant hypertension in young people. Arch Dis Child. 2001 Nov;85(5):401-3.

24. Mittal B V, Almeida A F. Malignant hypertension (a clinicopathologic study of 43 cases). J Postgrad Med [serial online]1987 [cited 2015 Aug 24 ];33:4954.

25. Chen YH, Kuo HK, Kao ML. Malignant hypertensive retinopathy-clinical and fundus manifestations in patients with new onset or acute exacerbation of chronic hypertension. Chang Gung Med J. 2003 Sep;26(9):669-77.

\section{How to cite this article?}

Telgote V, Singh A. Study of clinical and ophthalmic symptoms of malignant hypertension. Int J Med Res Rev 2015;3(9):996-1001. doi: 10.17511/ijmrr.2015.i9.184. 